\title{
Possibility of Strengthening Aluminum Using Low- Symmetry Phases of the Fe-Al Binary System
}

\author{
SYLWIA CIOŁEK, STANISŁAW JÓŹWIAK, and KRZYSZTOF KARCZEWSKI
}

\begin{abstract}
This study analyzes the effects of manufacturing parameters such as the temperature and heating time on the shape and size of high-aluminum-phase precipitates produced from a $95.5 \mathrm{wt}$ pct $\mathrm{Al}$ and $4.5 \mathrm{wt}$ pct Fe powder mixture. The samples were prepared by powder metallurgy, and the changes in the heat flux during the simulation of the sintering process by differential thermal analysis were recorded to determine the temperature of the transformation. To identify the resulting structures, microscopic observations (scanning electron microscope) and chemical composition analyses were performed simultaneously. The distribution and shape of the resulting high-aluminum-phase precipitates were determined. Microhardness measurements were also performed, and Meyer's law and Kick's similarity law were applied to the results to analyze the influence of the high-aluminum phases on the reinforcement of the aluminum matrix.
\end{abstract}

https://doi.org/10.1007/s11661-019-05110-6

(C) The Author(s) 2019

\section{INTRODUCTION}

MODERN design solutions require lighter and more durable materials. Composites consisting of light metals and other types of materials in various configurations have become increasingly feasible, thus creating new design possibilities. The most commonly known and used light metal is aluminum and its alloys. Pure aluminum is characterized by a low density $(2.7 \mathrm{~g} /$ $\mathrm{cm}^{3}$ ), which is its greatest advantage, and a high elongation value of up to 35 pct. However, it also has poor mechanical properties, such as low hardness $(18 \mathrm{HB})$ and strength $(70 \mathrm{MPa}) .^{[1]}$ To improve these properties, various elements are added to aluminum to modify the phase structure during either the crystallization step or heat treatment.

The two types of aluminum alloys include casting alloys, which mainly contain silicon, and wrought alloys. The latter group can be further subdivided into manganese and magnesium alloys, which are strengthened by work hardening, and copper and zinc alloys, which are strengthened by precipitation hardening. The properties of aluminum can be significantly enhanced by

SYLWIA CIOŁEK, STANISŁAW JÓŹWIAK, and KRZYSZTOF KARCZEWSKI are with the Department of Advanced Materials and Technologies, Faculty of Advanced Technologies and Chemistry, Military University of Technology, 2 Gen. S. Urbanowicza St., 00-908 Warsaw, Poland. Contact e-mail: sylwia.ciolek@wat.edu.pl

Manuscript submitted June 19, 2018.

Article published online January 24, 2019 strengthening mechanisms, and the fabrication of alloys which, together with its low density, has resulted in its wide use in various industries.

Despite the existence of a wide range of well-known aluminum alloys since the 1930s, numerous studies of reinforcement growth and the effects of various factors, such as the size and distribution of the precipitates, on the resulting mechanical properties have been and are still being performed. The study in this field is twofold. On one hand, research efforts are focused on modifying the production processes of well-known alloys by introducing new technologies, such as powder metallurgy, which was used to produce $\mathrm{Al}-\mathrm{Cu}$ alloys, ${ }^{[2]}$ or by tuning the chemical composition to produce reinforcing phases in the aluminum matrix. For example, Varin ${ }^{[3]}$ prepared $\mathrm{Al}-\mathrm{Zr}$ particles in an aluminum matrix to increase the hardness of the material. On the other hand, cheaper materials that are easier to use in the synthesis, such as iron, which is commonly used in construction materials, can be employed as reinforcing components. In his study, Srivastava showed that an Fe content ranging from 1.67 to 11.2 pct in aluminum-iron alloys significantly improves the alloy strength and tribological properties, due to the precipitation of the low-symmetry, high-aluminum phase $\mathrm{FeAl}_{3} \cdot{ }^{[4,5]}$ The undeniable potential of these particles to reinforce aluminum alloys is due to the complexity of the crystal structure, which gives rise to high hardness and abrasion resistance. ${ }^{[]}$In addition, these particles are cheaper than intermetallic phases containing other elements that are useful in construction. ${ }^{[7]}$ However, the production process must be modified to obtain high-aluminum precipitates with a suitable morphology and distribution throughout the 
material. The traditional production methods for alloys containing intermetallic phases are mainly based on melting and casting, which usually results in a coarse structure with low plasticity and brittle fracture. ${ }^{[8]}$ The resulting "technology gap" has been filled with production techniques based on powder metallurgy. ${ }^{[9]}$ In addition to its many well-known advantages, this technology enables the constitutive reinforcement of the alloy matrix by in situ methods, which, unlike ex situ particle reinforcement, leads to materials with high thermodynamic stability, i.e., the improved boundary between the matrix and reinforcing particles hinders potential degrading chemical reactions. ${ }^{[10]}$

In the $\mathrm{Fe}-\mathrm{Al}$ equilibrium system (Figure 1(a)), three high-aluminum phases, namely, $\zeta-\mathrm{FeAl}_{2}, \eta-\mathrm{Fe}_{2} \mathrm{Al}_{5}$, and $\theta-\mathrm{Fe}_{4} \mathrm{Al}_{13}\left(\mathrm{FeAl}_{3}\right),{ }^{[7]}$ exist at ambient temperature. Due to their low symmetry and the large volumes of their crystalline unit cells, they are characterized by high hardness, which makes them suitable for use as reinforcing phases (Table I). Their chemical compositions and transformation temperatures have been further refined. ${ }^{[11,12]}$ Due to the eutectic transformation $\mathrm{L} \rightarrow \mathrm{Al}(\mathrm{Fe})+\mathrm{Fe}_{4} \mathrm{Al}_{13}\left(\mathrm{FeAl}_{3}\right)$ at a temperature of $654{ }^{\circ} \mathrm{C}^{[15]}$ and $\mathrm{Fe}$ content of $\sim 1.8 \mathrm{wt}$ pct, ${ }^{[15]}$ and the relatively easy diffusion of the material in powder metallurgy, the $\theta$ phase can be obtained (Figure 1(b)).

Although the solubility of iron in aluminum is negligible (e.g., $0.012,0.024$, and 0.04 pct at $550{ }^{\circ} \mathrm{C}$, $590{ }^{\circ} \mathrm{C}$, and $630{ }^{\circ} \mathrm{C}$, respectively), only a very low content (several hundred ppm) of this element is needed to significantly inhibit dislocation movement in pure aluminum by affecting its strengthening mechanisms and creep resistance. ${ }^{[13]}$ Therefore, to enhance the $\mathrm{Al}(\mathrm{Fe})$ matrix strengthening, it was proposed that the $\mathrm{Fe}_{4} \mathrm{Al}_{13}$ phase $\left(\mathrm{FeAl}_{3}\right)$ could be used, because it limits warp deformation near the surface of each particle due to its elastic interactions with the matrix and its restraint of the dislocation motion. In this method of reinforcement, a hydrostatic stress field is generated around the reinforcing particles, which should be sufficiently large and uniformly distributed in the matrix volume and have similar, preferably spherical, shapes to ensure their efficiency. Achieving these requirements during eutectic crystallization is very difficult; therefore, in this study, we attempted to reinforce the aluminum matrix with low-symmetry Fe-Al phases produced in situ by diffusion through a mixture of aluminum and iron powders during a powder metallurgy process conducted in the eutectic temperature region.

\section{MATERIALS AND METHODS}

A detailed analysis of the Al-Fe equilibrium system in the eutectic area (Figure 2) shows that in addition to the stable $\mathrm{Fe}_{4} \mathrm{Al}_{13}\left(\mathrm{FeAl}_{3}\right)$ phase, metastable structures, such as $\mathrm{FeAl}_{6}, \mathrm{FeAl}_{m}{ }^{[8]}$ or $\mathrm{FeAl} l_{x}, \mathrm{Fe}_{2} \mathrm{Al}_{9}$, and $\mathrm{FeAl}_{p}$, ${ }^{[16]}$ can also form during the crystallization of an alloy with an approximately eutectic composition, depending on the process parameters, such as the temperature, cooling rate, etc. Accordingly, to determine which of these phases is most easily obtained by diffusion under

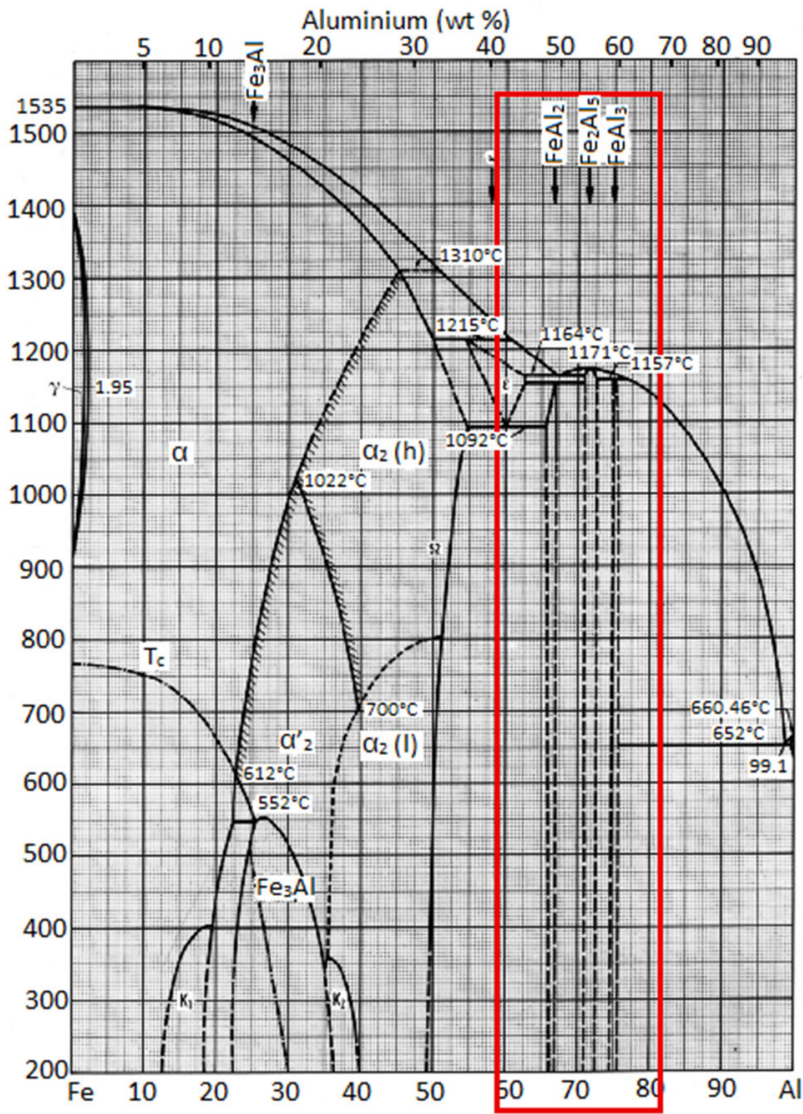

(a)

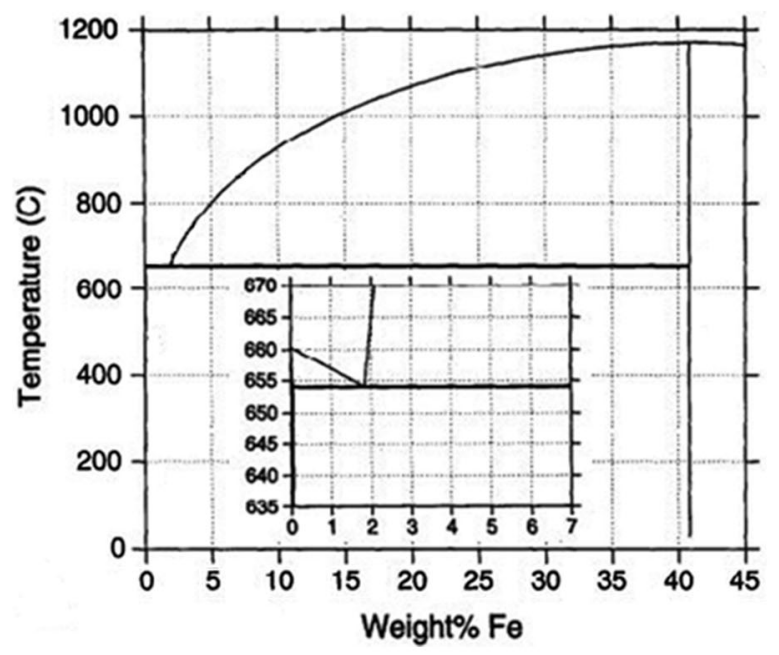

(b)

Fig. 1-Diagram of the Fe-Al equilibrium system indicating the regions where the high-aluminum phases exist $(a)$, from Ref. [14] with permission, and the eutectic transformation occurs $(b)$, from Ref. [16] with permission.

isothermal annealing conditions, a 4.5 pct $\mathrm{Fe}$ and 95.5 pct $\mathrm{Al}$ (by weight) powder mixture was used.

The prepared powders were mixed in a turbulent mill for 30 minutes and then compacted to a cylinder with a diameter of $3 \mathrm{~mm}$ and height of $5 \mathrm{~mm}$ by pressing the 
Table I. Selected Properties of High Aluminum Phases from the Fe-Al Binary System

\begin{tabular}{llcc}
\hline Phases & \multicolumn{1}{c}{ Structures } & Cell Volume $\left(\AA^{3}\right)$ & Hardness $(\mathrm{HV})$ \\
\hline $\mathrm{FeAl}_{2}$ & triclinic $P 1(1)$ & 263.69 & 892 \\
$\mathrm{Fe}_{2} \mathrm{Al}_{5}$ & orthorhombic Cmcm (63) & 206.55 & 903 \\
$\mathrm{FeAl}_{3}$ & monoclinic $C 2 / m(12)$ & 1487.88 & 691 \\
\hline
\end{tabular}

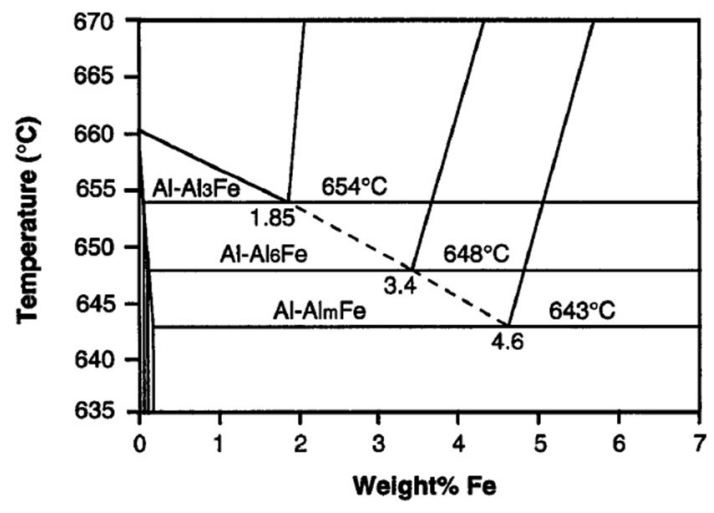

Fig. 2-Superposition of the stable $\left(\mathrm{Al}+\mathrm{FeA}_{13}\right)$ and metastable $\left(\mathrm{Al}+\mathrm{FeAl}_{6}\right.$ and $\left.\mathrm{Al}+\mathrm{FeAl}_{m}\right)$ eutectics in the $\mathrm{Fe}-\mathrm{Al}$ equilibrium system from Ref. [16] with permission.

sample on one side with a pressure of $700 \mathrm{MPa}$ to ensure a sequential equilibrium phase transition during the heating and cooling processes.

To record the changes in the heat flux during the phase change of the compacted samples, differential thermal analysis was performed to simulate the sintering process by heating from $610^{\circ} \mathrm{C}$ to $700{ }^{\circ} \mathrm{C}$ in 1 hour. Calorimetric analysis was performed to identify the precipitates and determine the temperature at which no reflections from the melting and crystallization of the test mixture are observed. At this temperature, the separation processes only occur by diffusion, which simplifies the subsequent technological processes and allows the reinforcing phase to be distributed throughout the entire volume of the alloy.

The microstructure, particularly the morphology and chemical composition of the resulting precipitates, was observed using a scanning electron microscope equipped with an energy-dispersive X-ray spectroscopy chemical composition analyzer. The results suggest that phase decomposition occurs during the analyzed process. To accurately determine the volumes of the high-aluminum phases produced in the aluminum matrix from the $\mathrm{Fe}-\mathrm{Al}$ system, computer-assisted quantum digitization was performed using the NIS ELEMENT software.

Microhardness measurements were performed to determine the changes in the degree of hardening as a function of the annealing temperature. In particular, 200, 300, and $500 \mathrm{G}$ loads were employed, the HV hardness was defined for a constant diagonal of $20 \mu \mathrm{m}$, and Meyer's law and Kick's similarity law were applied to the data. Using this approach, the effects of the elastic deformations on the hardness value and the Meyer's coefficient (strength factor), which characterizes the method of the material reinforcement, ${ }^{[6,18,20]}$ were determined.

\section{RESULTS AND DISCUSSION}

\section{A. Powder Characterization}

An analysis of the calorimetry curves obtained during the simulation of the sintering process (Figure 3(a)) reveals two distinctly different streams of heat flux. The first stream associated with the annealing temperature in the range of $610{ }^{\circ} \mathrm{C}$ to $630{ }^{\circ} \mathrm{C}$ (Figure 3(b)) does not appear to vary during the entire sintering cycle and therefore might be due to the slow phase change of the material during its formation by diffusion. The analyzed parameter varies for the samples sintered at $640{ }^{\circ} \mathrm{C}$ to $650{ }^{\circ} \mathrm{C}$ (Figure 3(c)), i.e., at the temperature at which the effects associated with the eutectic transformation are observed, according to the data presented in Figure 2. Specifically, an endothermic flux (marked by 2 ), due to the melting of the material, and exothermic flux (indicated by 3), which is typical for eutectic crystallization, are clearly observed. It should also be noted that the melting process is preceded by a slightly exothermic process (indicated by the number 1), namely the self-propagating high-temperature synthesis (SHS) at the boundaries of the iron and aluminum powder particles, which occurs at approximately $620^{\circ} \mathrm{C} .^{[18,21,22]}$ The heat released during this reaction facilitates the melting of the powder mixture, and the high-aluminum phases formed as a result of the SHS might serve as sites for the nucleation and growth of the precipitates during the cooling process. As shown in the calorimetric curve in Figure 3(c), a small increase in the heat flux is also observed at approximately $560{ }^{\circ} \mathrm{C}$. Similar although much weaker effects are also observed for samples sintered at $610{ }^{\circ} \mathrm{C}$ to $630{ }^{\circ} \mathrm{C}$. The effects of the diffusion process to form high-aluminum phases were also observed at approximately $560{ }^{\circ} \mathrm{C}$ in previous studies of phase formation in Fe-Al systems. ${ }^{[17,23-25]}$

The formation of high-aluminum precipitates in the aluminum matrix via two mechanisms is confirmed by the observed microstructure of the sintered product. The process at $630{ }^{\circ} \mathrm{C}$, which occurs only during steady-state diffusion, results in the formation of the high-aluminum phase $\mathrm{Fe}_{2} \mathrm{Al}_{9}$ mainly in the primary iron powder particles (Figures 4(a) and (b)). However, the observation of the structure at a higher magnification reveals the presence of numerous finely dispersed particles in the aluminum matrix (Figure 4(c)). Microanalysis of the chemical composition of the matrix shows that the iron 


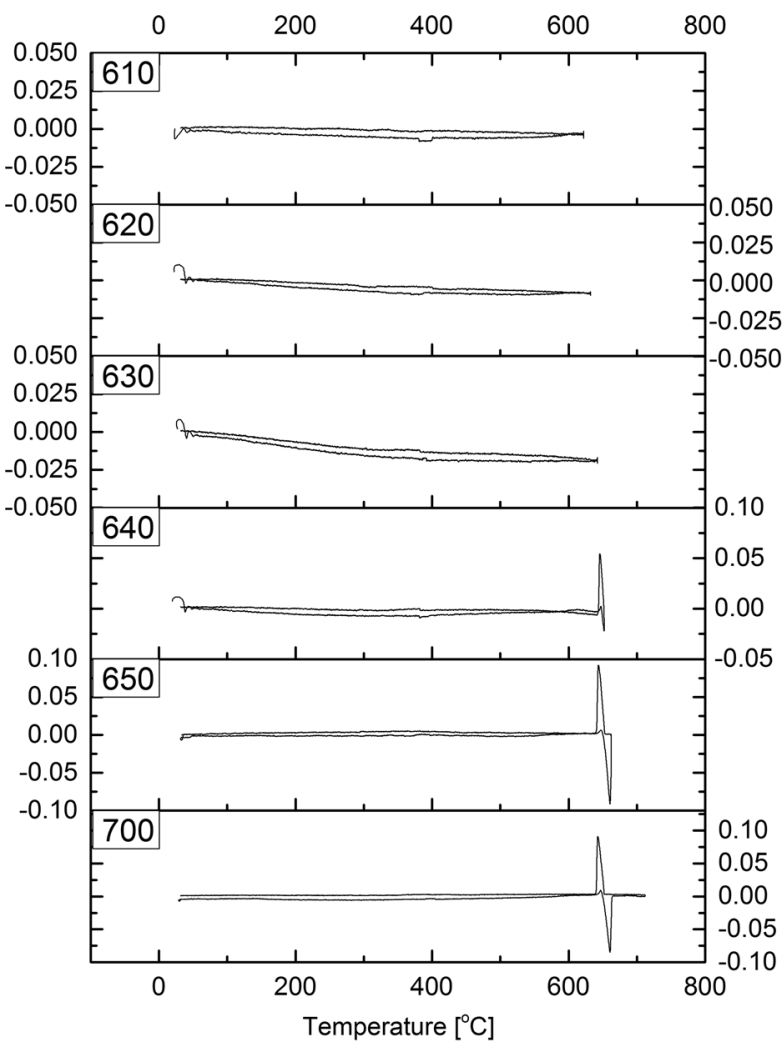

(a)

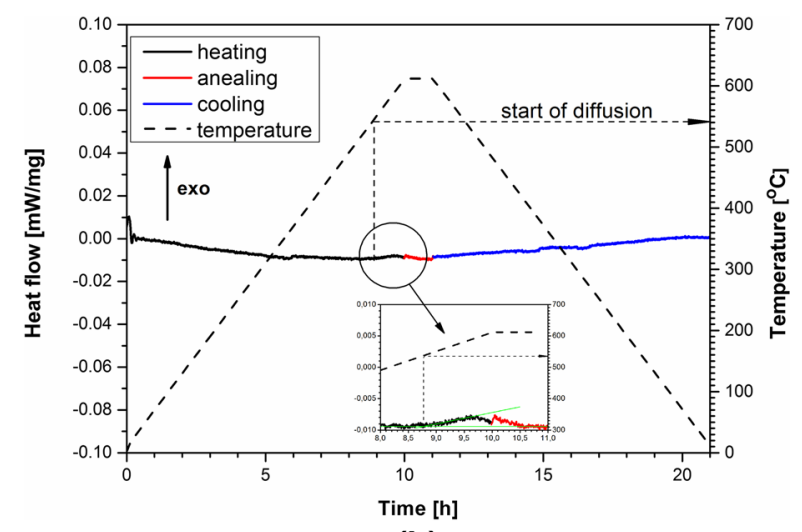

(b)

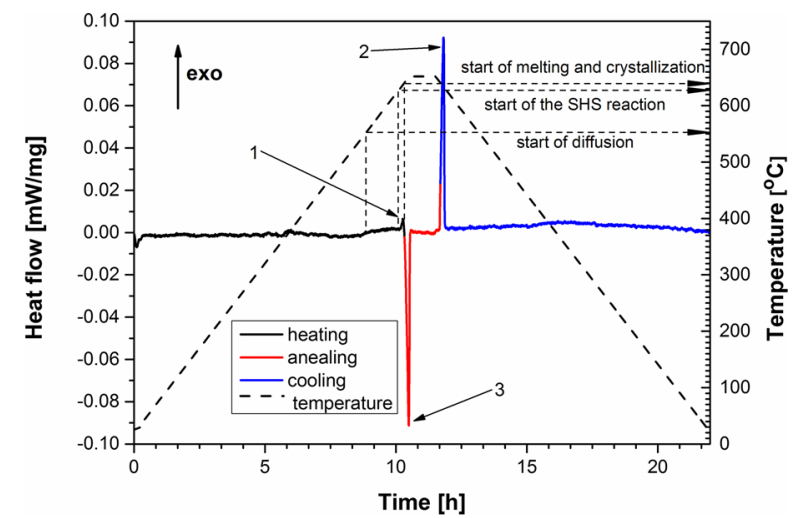

(c)
4Fig. 3-Two significantly different heat flux populations recorded during the simulation of the sintering process $(a)$, no apparent heat effects for the sample sintered at $610^{\circ} \mathrm{C}(b)$, obvious changes in the heat flux during the melting and crystallization of the sample sintered at $650^{\circ} \mathrm{C}(c)$.

content in the analyzed zone is approximately $0.46 \mathrm{pct}$ by weight. The maximum solubility of $\mathrm{Fe}$ in $\mathrm{Al}$ at the eutectic temperature is 0.04 pct by weight, suggesting that the diffusion through the system during sintering leads to the formation of the expected high-aluminum phase, which is assumed to have a reinforcing character.

The structure and morphology of the precipitates resulting from the overall process, during which melting and crystallization phenomena occur, are completely different. In addition to the previously observed large, diffusible, spherical $\mathrm{Fe}_{2} \mathrm{Al}_{9}$ precipitates formed in the primary iron powder particles, many needle-like particles that are typical of the eutectic structure and have a similar chemical composition are also observed (Figure 5(a)). At the same time, the iron content in the matrix is reduced by approximately $50 \mathrm{pct}$, and the proportion of finely dispersed particles that do not undergo melting and crystallization also decreases significantly. Thus, it is concluded that the microdispersions of the high-aluminum phases are also nucleation sites for the growth of one of the constituents of the resulting eutectic, i.e., they are involved in the phase separation of the needle-like $\mathrm{Fe}_{2} \mathrm{Al}_{9}$ particles (Figure 5(b)).

The effects of the temperature during the manufacturing process on the resulting microstructures and morphologies observed during diffusion, melting and casting undoubtedly influence the strength of the material produced. Indeed, the microhardness measurements reveal the significant influence of the resulting precipitates on the strengthening of the material produced (Figure 6).

The samples produced at $620^{\circ} \mathrm{C}$ to $630{ }^{\circ} \mathrm{C}$, i.e., under diffusion conditions, have many finely dispersed high-alumina precipitates in the matrix and have the highest hardness (HV0.1). Furthermore, the hardness determined by Meyer's law for a hypothetical diagonal of $20 \mu \mathrm{m}(\mathrm{HV} 20 \mu \mathrm{m})$ is the highest in this process temperature range (Figure 7).

It should be noted that at these sintering temperatures, the difference between HV20 $\mu \mathrm{m}$ and HV0.1, which is due to the effects of the elastic stresses generated in the matrix network, is assumed to be at a maximum. These observations are confirmed by the minimum value of the Meyer coefficient (strengthening), which varies around $n=1.7$. It is known that a decrease in the " $n$ " parameter corresponds to an increase in the strengthening rate of the material, and $n=1.6$ is the boundary between brittle and plastic materials. Increasing the process temperature above $630{ }^{\circ} \mathrm{C}$ results in the gradual disappearance of the resilient matrix stresses due to the melting and 

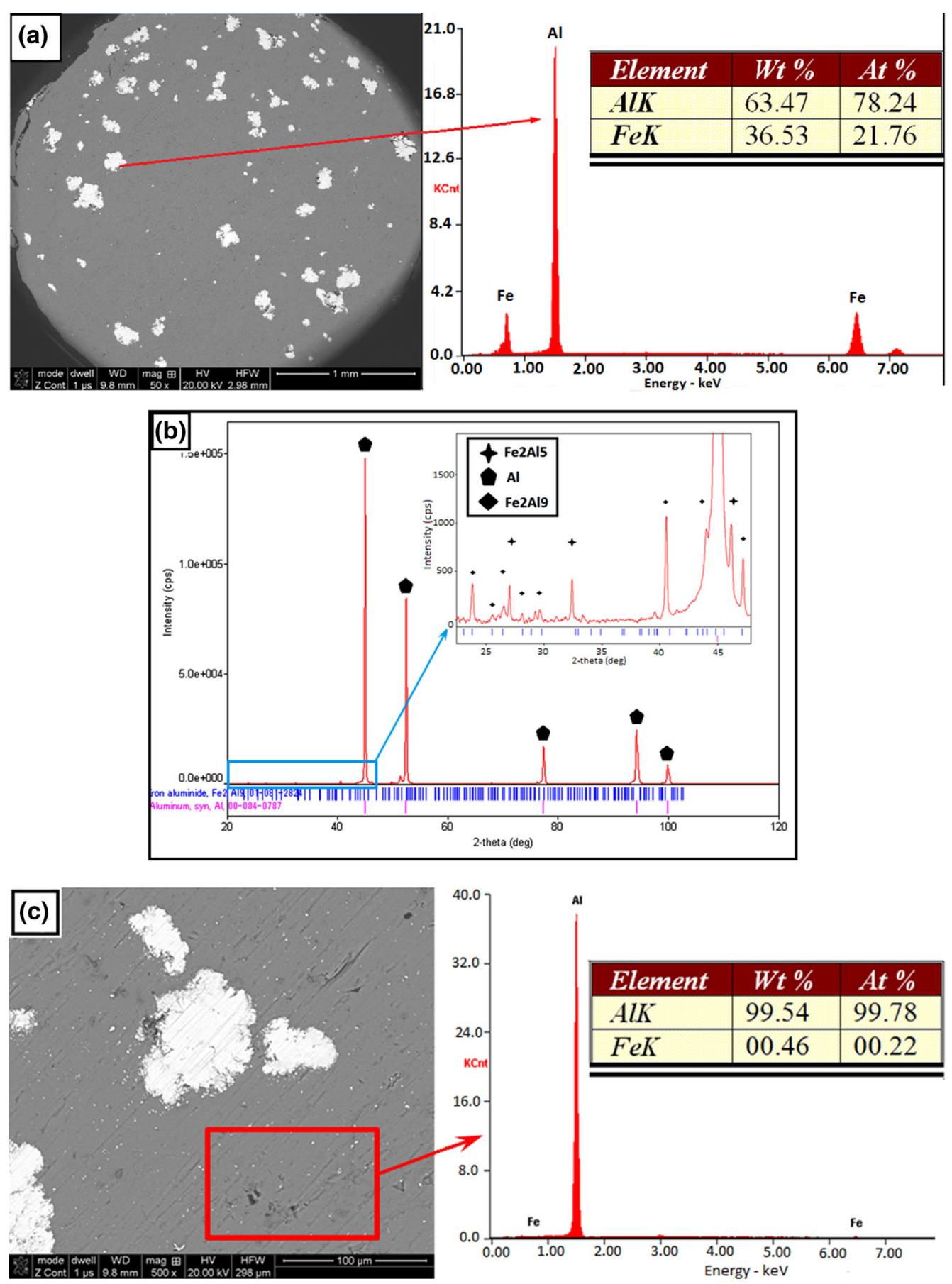

Fig. 4-High-aluminum phases formed within primary iron powder particles $(a)$ and their XRD pattern $(b)$, fine dispersion in the aluminum matrix $(c)$ during sintering at $630^{\circ} \mathrm{C}$.

crystallization processes, and $\mathrm{HV} 20 \mu \mathrm{m}$ and $\mathrm{HV} 0.1$ are essentially the same at $650{ }^{\circ} \mathrm{C}$ and higher. At the same time, a noticeable increase in the Meyer's coefficient is observed; at $650{ }^{\circ} \mathrm{C}$, it reaches the limit of $n=2$, at which the load does not affect the hardness value, meaning that the material is very difficult to strengthen under the measurement conditions. A further increase in the process temperature to $700{ }^{\circ} \mathrm{C}$ results in $n>2$, which is rare and results from brittle fracture (separation) at the boundary of the hard plastic matrix. ${ }^{[19]}$

The microhardness measurements are compared to the quantitative analysis of the observed precipitates in Figure 8. It can be concluded that the needle-like precipitates, which form as a component of the eutectic, 

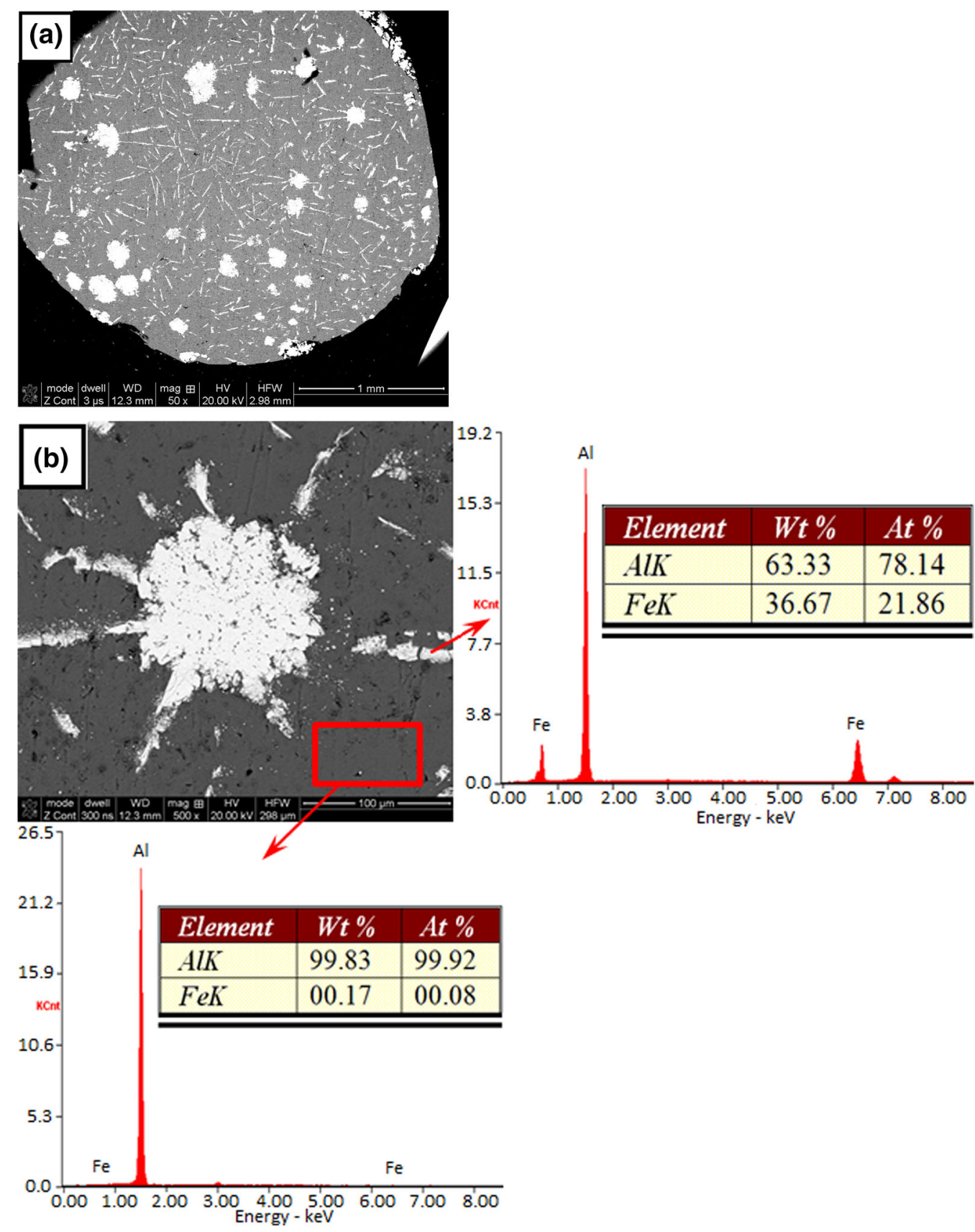

Fig. 5-Phase separation of spherical $\mathrm{Fe}_{2} \mathrm{Al}_{9}$ from the $\mathrm{Al}(\mathrm{Fe})+\mathrm{Fe}_{2} \mathrm{Al}_{9}$ eutectic $(a)$ and the noticeable disappearance of the finely dispersed particles from the alloy matrix after sintering at $650{ }^{\circ} \mathrm{C}(b)$.

do not affect the growth of the material to be strengthened. On the contrary, as the process temperature increases, they cause cracking. Because the large spherical particles are formed at the original iron particle sites regardless of the process temperature, the strengthening effect, i.e., the increase in the hardness, achieved at a sintering temperature of $620{ }^{\circ} \mathrm{C}$ to $630{ }^{\circ} \mathrm{C}$ can be attributed to the finely dispersed high-aluminum phases (Figure 4(b)), although their contribution to the effect is impossible to estimate.

\section{CONCLUSIONS}

In this study, the sintering process was simulated and analyzed by simultaneous calorimetry measurements; microscopic observations of the obtained structures; determination of the chemical composition, morphology, and distribution of the precipitates formed in the resulting material; and microhardness measurements, which led to the following conclusions: 
(1) It is possible to reinforce aluminum with high-aluminum phases of the Fe-Al binary system.

(2) The strengthening effect is most influenced by the morphology and distribution of the resulting phases, which depend on the temperature of the process.

(3) The most visible increase in the hardness is obtained when the samples are sintered at $620{ }^{\circ} \mathrm{C}$ to $630{ }^{\circ} \mathrm{C}$, which enables the generation

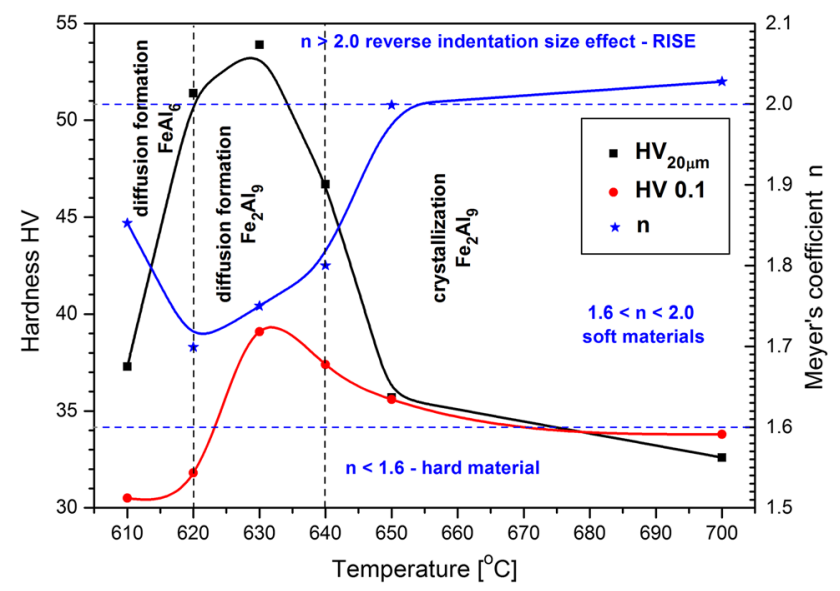

Fig. 6-Effects of the sintering temperature and the method used to obtain the high-aluminum phase on the hardness and Meyer coefficient of the produced material. of the highest number of finely dispersed particles in the aluminum matrix by diffusion.

(4) Under the studied process conditions, the resulting precipitates are identified as the metastable $\mathrm{Fe}_{2} \mathrm{Al}_{9}$ phase, which has been rarely described in the literature.

(5) It appears that the highest strengthening effect should be obtained by using iron powder with the least granulation.

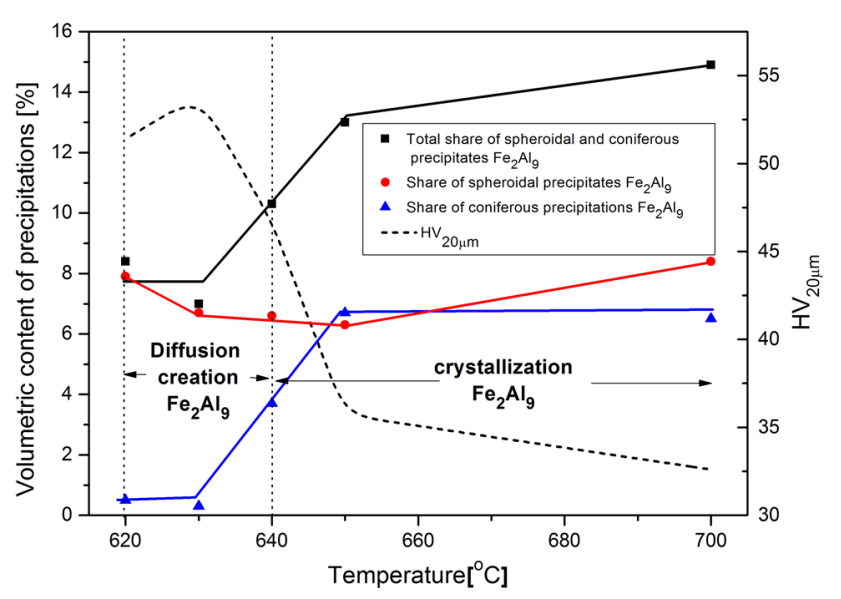

Fig. 8 - Comparison of the microhardness measurements with the quantitative analysis of the observed precipitates.

$$
F=a * d^{n}
$$

where:

F-load;

a-the load causing the unit

indentation

d-diagonal of the indentation

n-Meyerindex

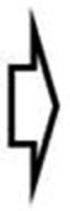

$$
\begin{gathered}
H V=0.1891 * \frac{F}{d^{2}}= \\
0.1891 * a \frac{d^{n}}{d^{2}}= \\
0.1891 * a d^{(n-2)}
\end{gathered}
$$

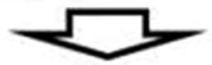

$\log F=\log a+n^{*} \log d$
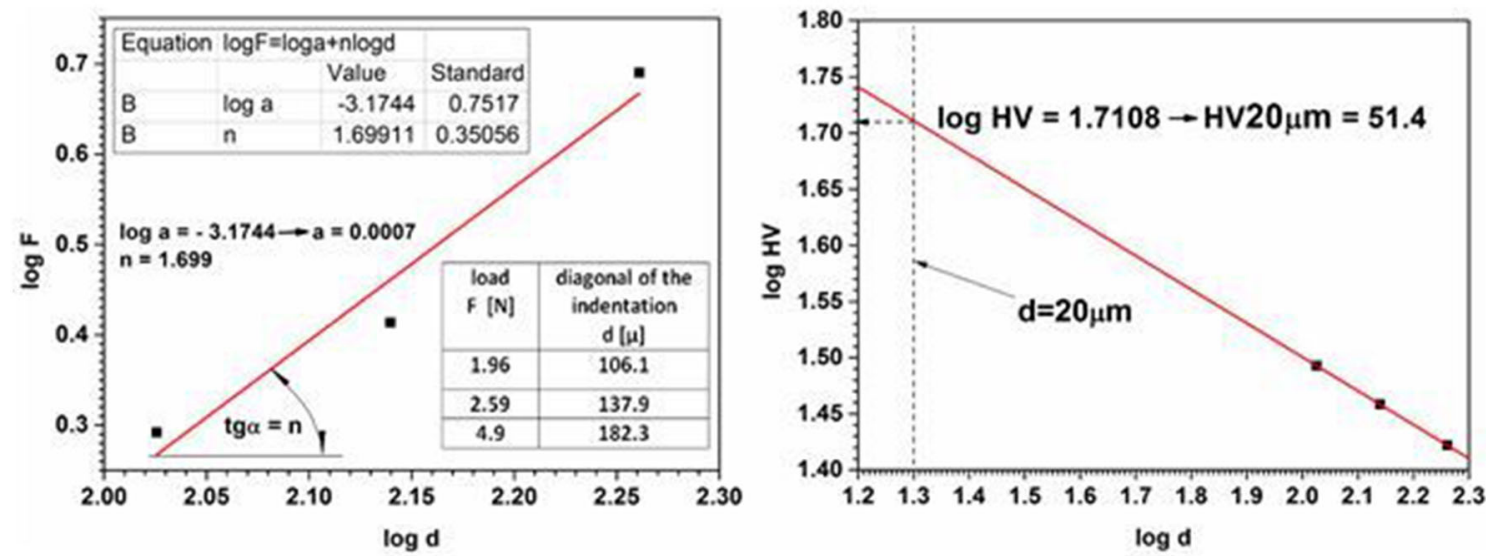

Fig. 7-Method of determining the Vickers hardness for a hypothetical diagonal $d=20 \mu \mathrm{m}$, according to Meyer's law, on the example of a sample produced at $620^{\circ} \mathrm{C}$. 
Future study in this area will focus on obtaining other $\mathrm{Fe}-\mathrm{Al}$ phases that strengthen the aluminum matrix, including the stable-phase $\mathrm{Fe}_{4} \mathrm{Al}_{13}\left(\mathrm{FeAl}_{3}\right)$, mainly by changing the heating rate and sintering time.

\section{OPEN ACCESS}

This article is distributed under the terms of the Creative Commons Attribution 4.0 International License (http://creativecommons.org/licenses/by/4.0/), which permits unrestricted use, distribution, and reproduction in any medium, provided you give appropriate credit to the original author(s) and the source, provide a link to the Creative Commons license, and indicate if changes were made.

\section{REFERENCES}

1. P. Matysik: Niskosymetryczne fazy z układu Fe-Al-identyfikacja strukturalna $i$ badanie właściwości, WAT, Warszawa, 2016, pp. 9-31.

2. M. Aravind, P. Yu, M. Yau, and H. Dickon: Mater. Sci. Eng., 2004, vol. 380, pp. 384-93.

3. R. Varin: Metall. Mater. Trans. A, 2002, vol. 33A, pp. 193-201.

4. S. Srivastava: Int. J. Sci. Res. Publ., 2012, vol. 2, pp. 1-14.

5. S. Srivastava: Int. J. Therm. Technol., 2012, vol. 2, pp. 1-10.

6. P. Matysik, S. Jóźwiak, and T. Czujko: Materials, 2015, vol. 8, pp. 914-31.
7. M. Ghomashchi: J. Mater. Process. Technol., 2001, vol. 112, pp. 227-35.

8. S. Jóźwiak: Aluminki żelaza - sekwencja przemian fazowych $w$ procesie nieizotermicznego spiekania proszków żelaza i aluminium, BEL Studio, Warszawa, 2015, pp. 32-78.

9. T. Durejko and Z. Bojar: Composites, 2002, vol. 2, pp. 323-27.

10. A. Dolata-Grosz, B. Formanek, J. Sleziona, and J. Wieczorek: Arch. Odlew., 2004, vol. 14, pp. 126-31.

11. K. Han, I. Ohnuma, and R. Kainuma: J. Alloy Compd, 2016, vol. 668 , pp. 97-106.

12. X. Li, A. Scherf, M. Heilmaier, and F. Stein: J. Phase Equilib. Diffus., 2016, vol. 37, pp. 162-73.

13. M. Shakiba, N. Parson, and X. Chen: Mater. Sci. Eng., 2014, vol. 619 , pp. $180-89$.

14. O. Kubaschewski: IRON-Binary Phase Diagrams, Springer, Berlin, 1982, pp. 5-9.

15. C. Allen, K. O'Reilly, B. Cantor, and P. Evans: Prog. Mater. Sci., 1998, vol. 481, pp. 89-170.

16. Ö. Pekgüleryüz and C.A. Aliravci: Calphad, 1998, vol. 22, pp. 147-55.

17. S. Jóźwiak, K. Karczewski, and Z. Bojar: Intermetallics, 2010, vol. 18, pp. 1332-37.

18. E. Poché́, S. Joźwiak, K. Karczewski, and Z. Bojar: J. Alloy Compd, 2011, vol. 509, pp. 1124-28.

19. H. Güder, E. Șahin, O. Șahin, H. Göçmez, C. Duran, and H. Ali Çetinkara: Acta Phys. Pol. A, 2011, vol. 6, pp. 1026-33.

20. O. Sahin, O. Uzun, U. Kolemen, and N. Ucar: Mater. Charact. 2007, vol. 58, pp. 197-204.

21. K. Karczewski, S. Jóźwiak, and Z. Bojar: Inż. Mater., 2007, vol. 28, pp. 552-58.

22. H. Sina, J. Corneliusson, K. Turba, and S. Iyengar: J. Alloy Compd, 2015, vol. 636, pp. 261-69.

23. S. Gedevanishvili and S. Deevi: Mater. Sci. Eng., 2002, vol. 325, pp. 163-76.

24. E. Pocheć, S. Józwiak, K. Karczewski, and Z. Bojar: Thermochim. Acta, 2012, vol. 545, pp. 14-19.

25. S. Józwiak, K. Karczewski, and Z. Bojar: Int. J. Powder Metall., 2009, vol. 45, pp. 40-44. 